\title{
Las reformas político-administrativas en el Ayuntamiento de la ciudad de México. 1765-1813
}

\author{
Political-Administrative Reforms in Mexico \\ City's Town Council. 1765-1813
}

\author{
Martha Leticia Espinoza Peregrino \\ Doctorante por el Instituto de Investigaciones Históricas \\ Universidad Michoacana de San Nicolás de Hidalgo \\ martlettiesper@hotmail.com
}

\begin{abstract}
Resumen
El texto estudia los cambios que ocurrieron en la estructura administrativa del Cabildo de la ciudad de México con la visita de José Antonio de Gálvez en 1765 hasta la promulgación de la Instrucción para el gobierno económico-político de las provincias de 1813. Muestra cómo cambió la organización del Ayuntamiento que primero estaba organizado por funciones, luego por tribunales y finalmente en comisiones, sin que se modificara en esencia su objetivo de orden y control de la ciudad. Analiza el establecimiento de regidores honorarios y la creación de la Contaduría de Propios, Arbitrios y Bienes de Comunidad de la ciudad de México, así como el primer impacto constitucional gaditano. Un aspecto muy importante es reconocer que estas disposiciones disminuyeron las facultades del Cabildo, con el fin de mantenerlo como una institución administrativa que fue perdiendo poco a poco sus facultades.
\end{abstract}

Palabras clave: reformas borbónicas; Ayuntamiento; ciudad de México; regidores honorarios; Constitución de Cádiz.

\begin{abstract}
This article analyzes the changes that took place in the administrative structure of Mexico City's town council following the visit of José Antonio de Gálvez in 1765, until the enactment of the 1813 Instruction for the economic-political government of the Provinces: first by functions, then by tribunals and finally in commissions, without essentially modifying its objective of organizing and controlling the city. It studies the establishment of honorary councilors and the creation of Mexico City's Accounts of Income from Property Rental, Arbitrations and Community Goods, and Cádiz's first constitutional impact. Importantly, these provisions reduced the city council's power, in order to maintain it as an administrative institution that gradually lost its faculties.
\end{abstract}

Key words: Bourbon reforms; city council; Mexico City; honorary councilors; Cadiz Constitution.

Fecha de recepción: 8 de mayo de 2014 Fecha de aceptación: 29 de agosto de 2014

Secuencia, ISSN 0186-0348, núm. 94 | enero-abril de 2016 | pp. 77-109 


\title{
Las reformas político-administrativas en el Ayuntamiento de la ciudad de México. 1765-1813
}

\author{
Martha Leticia Espinoza Peregrino
}

$\mathrm{E}$ objetivo del texto es analizar de qué manera se llevaron a cabo los primeros intentos hacia la nueva ordenación del Ayuntamiento a raíz de los cambios en la administración monárquica española con la llegada al trono de la familia Borbón. Para ello el estudio se centra en el establecimiento de la Contaduría de Propios, Arbitrios y Bienes de Comunidad de la ciudad de México con la que se creó dentro del Cabildo una Junta de Propios y Arbitrios, la cual tenía a su cargo elaborar un reglamento particular para organizar las entradas y salidas de caudales de sus arcas, lo que trajo como consecuencia la incorporación de Regidores Honorarios a la junta concejil (Merchan, 1988, pp. 201-260). ${ }^{1}$

Dentro del Cabildo ocurrió una serie de reformas hasta la promulgación de la Instrucción para el gobierno económico-político de las provincias de 1813; sin embargo, por el momento sólo se abordarán las ya enunciadas porque se considera que muestran cómo cambió la organización del Ayuntamiento que primero estaba constituido por funciones, luego por tribunales, y finalmente en comisiones, sin que se modificara en esencia el objetivo de orden y control de la ciudad.

De acuerdo con lo anterior, es importante reconocer que las reformas borbónicas concernientes al Cabildo fueron con el objetivo de ordenar la administración a través de criterios racionales como definición de funciones, especialización y profesionalización de los funcionarios públicos y separación de los asuntos judiciales de los burocráticos para señalar líneas de autoridad con una tendencia hacia la centralización.

${ }^{1}$ Ayuntamiento y Concejo son términos equivalentes para designar al Cabildo o regimiento al que se considera como la reunión de vecinos que delibera sobre la forma de administrar la ciudad para vigilar que cada uno de los habitantes tuviera lo que le correspondía, por lo que tenía amplias facultades para decidir sobre su forma de gobierno en un espacio territorial determinado. 
En adición, se debe subrayar que este es un trabajo sobre el Ayuntamiento, entendido como la institución encargada del gobierno de la ciudad; no se analiza la urbe en sí misma, pues los estudios sobre centros urbanos concretos, como señala Carmen García (1996) deben tomar en cuenta los elementos sociales para dejar en claro las características de una ciudad. El estudio del Cabildo, en cambio, debe ser a partir de elementos políticos y administrativos que conforman un Estado. Las reformas llevadas a cabo por los reyes españoles durante el siglo XVIII dan la pauta para preguntarnos sobre la puesta en práctica de nuevos planteamientos en una sociedad de antiguo régimen y de qué manera dichos proyectos se reflejaron en la estructura de la organización al interior del Cabildo.

La investigación se centra en el Ayuntamiento de la ciudad de México sobre el cual aún no se ha realizado un estudio que lo analice como parte de todo un engranaje monárquico y las repercusiones que las medidas giradas por Carlos III tuvieron en el ambiente del corregimiento que para algunos fue el más importante de la América española, por lo que este se puede considerar como una primera aportación a esta discusión. La ciudad de México es el escenario de los conflictos de delimitación jurisdiccional y de funciones entre las tres autoridades con injerencia en la ciudad: el virrey, la Real Audiencia y el Ayuntamiento, y posteriormente la injerencia del intendente-corregidor establecido en 1786 . Esta complejidad de la ciudad capital es un marco excepcional para comprender la disputa por la autoridad gubernativa. ${ }^{2}$

Las transformaciones que se llevaron a cabo dentro del Cabildo de la ciudad de México durante la segunda mitad del siglo xvin deben entenderse dentro del contexto del nuevo proyecto de Estado español que comenzó con la llegada de los Borbón a la corona española al comenzar ese siglo. Dichos cambios tenían el objetivo de generalizar las normas para consolidar una nueva nación con los mismos lineamientos jurídicos y administrativos. Para fortalecer este propósito de unificación y centralización se tenían que tomar en cuenta todos los niveles del gobierno monárquico, pues el proyecto borbónico consistía en crear un Estado administrativo que estuviera al servicio de las necesidades financieras de la metrópoli. Para lograr semejante sistema la corona tenía que limitar las facultades tradicionales de las corporaciones

${ }^{2}$ La ciudad de México ha sido estudiada desde el ámbito de la historia urbana. Cuando se ha realizado la mancuerna entre esta ciudad y su Cabildo es para analizar la vida social (Aguirre, 2000); la obra pública (Dávalos, 1997); o el abasto de mercancías (Florescano, 1969) por citar sólo algunos ejemplos.

\section{(ㄷ)(1) $\$$}


y sus funcionarios (Domínguez, 1990, pp. 3-10; Reinhard, 1997, pp. 83-105). Eliminar diferencias entre ayuntamientos, recuperar impuestos arrendados, crear programas uniformes con los cuales evitar contradicciones de carácter administrativo y consolidar una estructura para aminorar las disparidades locales, eran aspectos clave para lograr una cohesión política. Había que definir funciones y líneas de autoridad, así como separar los asuntos judiciales de los burocráticos para crear un Estado administrativo donde la línea de mando tendía hacia la centralidad, es decir, sistematizar para centralizar (Bonnin, 2003; Guerrero, 1994, pp. 115-169).

\section{LOS PROPIOS Y ARBITRIOS DEL AYUNTAMIENTO DE LA CIUDAD DE MÉXICO}

Los ayuntamientos de las ciudades novohispanas, de la misma manera que las hispanas, habían conseguido como parte de sus privilegios otorgados por el rey al momento de la creación de los ayuntamientos, la capacidad de administrar sus caudales y definir la forma de obtenerlos, así como el modo de gastarlos siempre con el visto bueno del rey. De esta manera, los ayuntamientos consideraban los ingresos locales de su propiedad y la distribución de los gastos como su derecho.

Los cabildos obtenían sus ingresos a través de los propios y arbitrios. De manera general se puede decir que ambos eran el conjunto de bienes y servicios que proporcionaban al Ayuntamiento una ganancia fija con la que anualmente debía planificar el sostenimiento del aparato burocrático en que se sostenía. Las entradas de propios y arbitrios debían solventar las obligaciones que acarreaba la corporación que representaba los intereses de la ciudad y financiar las prestaciones que la vida urbana requería. Si bien los ingresos debían cumplir con los gastos para cuidar del orden y bienestar de la ciudad se tenía que cubrir los sueldos de los regidores, además lograr que la Hacienda Real disfrutara de una parte de estos fondos por lo que una cantidad de lo recaudado debía enviarse a España. Fonseca y Urrutia (1845) los definieron de la siguiente manera:

Llámense propios de las ciudades, villas y lugares aquellas tierras, terrenos o derechos, concedidos por la potestad suprema, en cuyos productos libre el público el desahogo de sus cuidados, y cuando estos no le alcanza, se echa mano de lo que se conoce con nombre de arbitrios, adquiriendo unos y otros

\section{()(1) $\$$}


la privilegiada naturaleza de no poder invertirse en diversos destinos ni dejar de llevarse una cuenta y razón clara de su distribución, a cuyo fin los desvelos soberanos se han esmerado en crear oficinas, a cuyo cargo corran asuntos tan interesantes (vol. v, p, 243. Las cursivas son mías).

Se pueden considerar como propios los ejidos que se encontraban dentro de sus límites territoriales que podía administrar como parte de su patrimonio. Además de estos pastos, el Cabildo contaba con edificios que eran arrendados como habitación de los vecinos, o como tiendas dentro del portal de los mercaderes. También eran de su propiedad las plazas y plazuelas donde se establecían los mercados, el matadero y las carnicerías, por los cuales recibían una renta por parte de los expendedores. También pueden considerar como propios los servicios como alumbrado, empedrado, limpieza de calles, desagüe de la ciudad, abasto de carne (en caso de no presentarse un particular para ocupar el cargo de obligado), inspección de pesas y medias para mantenerlas equilibradas ya que eran servicios que debían realizar los regidores pero que se subastaban a particulares (Pazos, 1999, pp. 169-170).

Los arbitrios eran los impuestos concejiles como el derecho de las derramas de agua, las ganancias del pósito y la alhóndiga y la introducción de vino y licores producidos en Nueva España. Estas rentas eran administradas por el Cabildo a través de la mesa de propios y arbitrios que estaba conformada por el superintendente de propios, el procurador general, el contador de propios y el tesorero mayordomo de propios. ${ }^{3}$

\section{LA INSPECCIÓN DE JOSÉ ANTONIO DE GÁLVEZ A LOS PROPIOS Y ARBITRIOS DE LA CIUDAD DE MÉXICO}

Con el propósito de promover las reformas que ya se habían gestado en España, en 1765 se envió a José Antonio de Gálvez como visitador, cargo que concluyó en 1771. Esta visita tenía la encomienda de revisar todos los tribunales de Justicia y de Real Hacienda así como tener conocimiento de los caudales

${ }^{3}$ Cuentas de Propios y Arbitrios de la ciudad de México. Estado de sus propios, núm. 1, 1811. Fondo Ayuntamiento. Sección Historia. Visita de Gálvez. Vol. 2294, exp. 35. Archivo Histórico del Distrito Federal (AHDF), México. Estado que manifiestan los propios y rentas de la ciudad de México de los ramos de pósito y fondo de obras públicas, 1768-1789. Fondo Ayuntamiento. Sección Hacienda. Propios. Vol. 2228, exp. 1. AHDF, México.

\section{(이요 $(9$}


de propios y arbitrios de todas las ciudades y pueblos comprendidos en el virreinato de Nueva España. La intención de Carlos III, según la instrucción reservada dirigida a Gálvez, era aumentar los ingresos reales, sin crear nuevos impuestos, que difícilmente aceptarían los súbditos novohispanos por considerarlos injustos (Suárez, 2002). El deseo de la corona era ampliar sus entradas a través de un mayor control de los sujetos y de un registro más eficiente de las tributaciones ya existentes a través de la definición y el reconocimiento de los que podrían ofrecerle mayores sumas de dinero. Este control de las tributaciones fue planeado a través de una reforma muy amplia en la organización administrativa de la Hacienda Real, a la que siguió una regulación de la Hacienda concejil (Jáuregui, 1999, pp. 55-57).

El decreto girado en Madrid, en abril de 1760, sirvió de base a José de Gálvez para intervenir en los caudales concejiles. En él se mencionaba que cada Cabildo debía elaborar su propio reglamento de ingresos y gastos. Este reglamento tenía que ser conocido por la Contaduría General de Propios y Arbitrios del Reino, la cual estaba directamente relacionada con el Consejo de Castilla (Tanck, 1999, p. 17). En 1765 el monarca dispuso la creación de la Contaduría General de Propios y Arbitrios del Reino de Nueva España, donde se llevaría la cuenta y razón de las Haciendas locales. Se dispuso eliminar el cobro de $4 \%$ sobre los arbitrios dirigidos a la Real Hacienda, y en su lugar se cobraría $2 \%$ de lo recaudado de todos los propios los cuales servirían para cubrir los salarios y gastos de administración. A esas oficinas tenían que llegar los reglamentos particulares de cada ciudad, incluida la ciudad de México y sus oficinas subalternas (Fonseca y Urrutia, 1845, vol. v, pp. 244-245).

En el Cabildo de la ciudad de México la tarea era revisar las cuentas de propios y arbitrios para reconocer las rentas generadas por la ciudad, así que el Ayuntamiento nombró a don Joseph de Gorraez y don Juan Lucas de Lassaga como diputados que debían facilitar los documentos y cálculos necesarios para agilizar la revisión de los balances del Concejo. Sin embargo, el Ayuntamiento inició una disputa contra el visitador, pues advertía que en la ordenanza no se señalaba de manera puntual que la ciudad estuviera incluida en dicha visita, y por ser la cabeza del virreinato no era necesario ese tipo de reconocimiento pues sus cuentas siempre habían sido claras.

${ }^{4}$ En Madrid se le conocía como la Contaduría General de Propios y Arbitrios, y en Nueva España tomó el nombre de Contaduría de Propios, Arbitrios y Bienes de Comunidad, porque en el virreinato los pueblos de indios tenían como ingresos concejiles los bienes de comunidad.

\section{()(1) $(9$}


Los argumentos presentados por el Cabildo mencionaban que esta visita tenía tintes de un juicio de residencia, pues se estaban estudiando las entradas y salidas de dinero de las arcas concejiles, pero que ninguna ley apoyaba dichas acciones. El Ayuntamiento indicaba que si el tenor de la orden era revisar las cuentas dicha tarea ya se cubría desde 1717 al establecerse por real cédula de 29 de noviembre el Ministerio de la Conservaduría. Al instaurarse el Ministerio de la Conservaduría, se creó la Superintendencia de Propios, la cual "es una rigurosa Delegación del soberano", con facultades para facilitar el trabajo del superintendente, por lo que la visita haría ocioso el cargo del conservador que el rey no había revocado. ${ }^{5}$

El Cabildo evitaba que Gálvez recibiera los estados de cuenta de la ciudad y argumentaba que en ninguna parte la instrucción señalaba que la ciudad estuviera incluida en la revisión de cuentas y que parecía más bien una comisión independiente a la ordenanza; es decir, por mera voluntad del visitador. Este solicitaba que se le hicieran llegar los estados de cuenta del Ayuntamiento; sin embargo, los regidores señalaban que no tenían conocimiento de los capítulos de la instrucción que hablaban sobre este particular. Ante esto, los regidores acordaron, en cabildo secreto, revisar los artículos que pudieran modificarse para lograr los medios que les permitieran satisfacer los deseos del visitador. Asimismo se acordó mandar una representación a Madrid en la que se manifestaría la lesión a los fueros y privilegios de la nobilísima ciudad y que mientras se recibiera una decisión de la corona, las cosas debían continuar como hasta ese momento.

El 7 de abril de 1768, José de Gálvez ordenó recolectar información detallada sobre las finanzas de las ciudades y los pueblos con el propósito de crear reglamentos individuales que especificaran los gastos permitidos y a la vez exigieran el envió anual de las cuentas concejiles para su aprobación a la Contaduría General de Propios y Arbitrios. La finalidad de esta acción era que la ciudad debía sostenerse de sus recursos y ahorrar lo más posible en gastos de administración urbana, sin dañar a los vecinos y obtener una mayor cantidad de dinero que fuera a parar a las arcas reales (Suárez, 2002, p. 134).

Luego de dictar esas determinaciones, Gálvez salió de la ciudad de México hacia las Provincias Internas para continuar con su tarea de visitador real. Debido a esto nombró a José Antonio de Areche como subdelegado de

5 Testimonio de la instancia de la N. C. de México, sobre exonerarse de la visita subdelegada al señor D. José Antonio de Areche. 1768. Instituciones Coloniales. Ayuntamiento. Contenedor 72, vol. 210, exp. 1. Archivo General de la Nación (AGN), México.

\section{()(1) $\$$}


su visita, con el encargo de continuar con el control de los propios y arbitrios del Cabildo de la ciudad de México (Suárez, 2002, pp. 133-137). ${ }^{6}$ Areche solicitó permiso al Cabildo para ingresar a la sala del Ayuntamiento, para lo cual presentó la orden dada por el delegado real. Acto seguido, el subdelegado solicitó se le presentasen los papeles necesarios para la inspección de propios. Ante este panorama, el Concejo convocó a junta con el superintendente de Propios y Arbitrios, pues dichas disposiciones tocaban directamente las tareas del Cabildo en materia de Hacienda. ${ }^{7}$

El 5 de mayo de 1768, el Ayuntamiento solicitó a José Antonio de Areche, tal como en su momento lo hizo con Gálvez, el documento en que se estipulase que la Ordenanza de 25 de marzo de 1765 también incluía la revisión de las cuentas de la ciudad capital. La representación que Areche envío al Cabildo señalaba que sólo había procedido de acuerdo con lo dispuesto por Gálvez y mencionaba como una evasiva la constante solicitud de este documento para responder a una decisión no sólo de Gálvez, sino del rey, quien había otorgado todas las facultades al visitador con el propósito de resolver los problemas presentados en toda Nueva España. El virrey Carlos Francisco de Croix intervino y pidió al Ayuntamiento que se prestaran al oidor Areche los documentos que necesitase para la inspección. Sin embargo, el Cabildo acordó que ningún escribano entregase papeles sin que se recibieran órdenes de esta ciudad.

Por esos días la corporación elevó una representación al rey para evitar la intromisión de Areche en las cuentas del Cabildo. En dicho documento los regidores alegaban que Gálvez no tenía poder del rey para intervenir en los balances de las ciudades y sí en las de villas y pueblos de indios. Mucho menos podía delegar en un funcionario (para el caso un oidor moderno de la Real Audiencia) esta tarea. Como respuesta, Carlos III ratificó las facultades que tenía su funcionario para realizar dichas investigaciones con la ayuda de otros oficiales nombrados bajo la discreción del visitador, debido a que la tarea encomendada era muy grande y el rey estaba consciente que era una labor demasiado amplia para ser cumplida por un solo hombre. Por ello, la instrucción real recibida por Gálvez le otorgaba la facultad para nombrar "visitantes como sus suplentes". No obstante, los regidores no admitían tener trato con una persona no nombrada por el rey sino por un delegado, lo

${ }^{6}$ José Antonio de Areche en ese momento era oidor de la Real Audiencia de México.

7 Actas de Cabildo de sesiones originales. 1768. Fondo Ayuntamiento. Gobierno del Distrito Federal. Sección Ayuntamiento. Vol. 88-A. AHDF, México.

\section{(ㅇ)(1) $\$$}


que hería su imagen de cabeza de la ciudad, pues uno de sus privilegios era mantener correspondencia directa con el monarca. Así, los integrantes del Ayuntamiento no entendían por qué el rey no se dirigía de manera directa al Concejo de la ciudad. ${ }^{8}$

Las disputas de los regidores con Areche eran frecuentes. Incluso las relaciones entre el Cabildo y el visitador subdelegado se tornaron tirantes debido a que este no recibió en su casa al regidor Aguirre, quien deseaba consultar con él negocios del regimiento. Este desaire a un representante del Cabildo se tomó como una afrenta a toda la corporación, pues el oidor mostraba signos de desinterés por los problemas de organización que las reformas traían consigo en el orden del Ayuntamiento. En la Junta de Cabildo se llegó al acuerdo que sólo se tendría contacto con el subdelegado del visitador a través de cartas, lo que atrasaba aún más las tareas de Areche.

Parece ser que la corporación evitaba por todos los medios contestar a las misivas y es hasta que el marqués de Croix intervino cuando se reanudaron las relaciones entre el Concejo y el subdelegado de Gálvez. El virrey solicitó al corregidor que citara a Cabildo para hacer saber a los caballeros capitulares lo irregular de su proceder al entretener la orden de dar a conocer sus balances y prescribió al Consejo no causar más demora a la tarea del fiscal Areche. Así como devolver a su dueño los documentos presentados para validar la tarea encomendada por Gálvez. ${ }^{10}$

Los argumentos del regimiento se basaban en distintas reales órdenes emitidas durante el siglo XVII, en las que se otorgaba el privilegio de no admitir mayores intervenciones en sus caudales que los realizados por el superintendente de propios. Sin embargo, el virrey señalaba que estas nuevas disposiciones dejaban sin efecto las expedidas con anterioridad, pues el rey había enviado órdenes precisas en su instrucción reservada al visitador. Para Croix la solicitud del Ayuntamiento de conocer la instrucción reservada era improcedente, pues ella sólo tenía que llegar a manos del virrey, quien era el

8 Triplicado del oficio dirigido al Sr. Ministro recomendándole el negocio de propios y arbitrios que gira en la Corte de Madrid, con motivo de la Subdelegación que hizo el Sr. Visitador con el Sr. Areche, 1768. Fondo Ayuntamiento. Gobierno del Distrito Federal. Sección Historia. Visita de Gálvez. Vol. 2294, exp. 2. AHDF, México.

${ }^{9}$ La llamada Junta de Cabildo, era el término utilizado para designar la reunión entre el corregidor y los regidores, sin intervención de los oficiales auxiliares, es decir, sólo participaba el Cabildo cerrado.

${ }^{10}$ Acta de Cabildo de sesiones ordinarias. 1769. Fondo Ayuntamiento. Gobierno del Distrito Federal. Sección Ayuntamiento. Vol. 89-A. AHDF, México.

\section{()(1) $\$$}


representante del rey en el reino, y no debía llegar a ninguna otra persona o corporación. ${ }^{11}$

El subdelegado del visitador le hizo saber al virrey Croix que posiblemente la negación de los regidores a la visita se debía al temor de ser descubierto el desinterés por la ciudad y las malversaciones en sus propios y no por un deseo de proteger sus regalías como corporación. De otra manera no entendía la pereza y repugnancia que los ediles presentaban ante la tarea que le había sido encomendada, aun cuando él había tratado de conducirse de la manera más cauta y respetuosa para dirigirse a una corporación tan importante como el Cabildo. De igual forma consideraba imposible llevar a cabo su tarea de revisar los ingresos de la ciudad debido a la poca disponibilidad del regimiento que dejaba entrever "la enfermedad política que aquejaba a la república, no sólo en la de México sino en todas las otras ciudades, villas y lugares de esta gobernación". ${ }^{2}$

\section{EL ESTABLECIMIENTO DE REGIDORES HONORARIOS EN EL AYUNTAMIENTO DE LA CIUDAD DE MÉXICO}

El principal elemento que evitaba el buen manejo de las rentas concejiles eran, según José Antonio de Areche, los regidores quienes habían adquirido el cargo por compra y no permitían que la ciudad brillara conforme a la importancia que merecía al ser la más grande y populosa de Nueva España. Areche se percató que para continuar con la tarea encomendada por Gálvez era necesario realizar modificaciones en la organización administrativa del Cabildo. De esa manera se podría lograr que personas fuera de los intereses concejiles tuvieran la facultad para administrar las rentas. Por ello recomendó el establecimiento de regidores honorarios y un síndico procurador del común, a semejanza de lo establecido en Madrid, según el oidor, con mucho éxito.

De acuerdo a lo proyectado por José Antonio de Areche, con la creación de estos cargos se intentaba reforzar las resoluciones sobre el arreglo

${ }^{11}$ Testimonio de la instancia de la N. C. de México sobre exonerarse de la visita subdelegada al señor D. José Antonio de Areche. 1768. Instituciones Coloniales. Ayuntamiento. Contenedor 72, vol. 210, exp. 1, f. 3. AGN, México.

${ }^{12}$ Testimonio de la instancia de la N. C. de México, sobre exonerarse de la visita subdelegada al señor D. José Antonio de Areche. 1768. Instituciones Coloniales. Ayuntamiento. Contenedor 72, vol. 210, exp. 1, f. 3. AGN, México.

\section{(ㅇ)(1) $\$$}


de propios y arbitrios, pues estos funcionarios debían vigilar que las nuevas disposiciones sobre estos asuntos se llevaran a cabo. ${ }^{13}$ Sin embargo, una de las representaciones hechas a Croix por Areche deja entrever que la decisión de incorporar nuevos integrantes al Cabildo se debió a la poca disponibilidad de los ediles para dejar entrar al subdelegado del visitador a la casa de cabildo y conocer las cuentas de la ciudad. ${ }^{14}$

En la península, los regidores honorarios fueron creados con la intención de devolverle al Concejo su esencia de representante de los vecinos, pero con la condición que estos no formaran parte de alguna de las familias que habían retenido el poder local durante todos esos años. Así, se estipulaba en la ordenanza que los regidores honorarios no debían ser familiares de algún integrante del Cabildo hasta una cuarta generación. ${ }^{15}$

La historiografía sobre esta reforma en España señala que el establecimiento de regidores honorarios permitió la injerencia de nuevos actores políticos que representaban a los habitantes de la ciudad, designados en una elección universal, inorgánica, indirecta y anual. La elección era una concesión real que formaba parte del patrimonio del pueblo y como una manera de paliar la injerencia de regidurías por venta que sólo menoscababa el ejercicio del Cabildo, por lo que no era una nominación con tintes liberales pues el objetivo era intervenir en el Concejo para regular sus funciones en beneficio del control monárquico. (García-Baquero, 1993, pp. 52-56; Guillamón, 1980, pp. 25-27).

En cuanto a su establecimiento en Nueva España, Jaime E. Rodríguez O. (2005) señala que en la década de 1770 se llevaron a cabo elecciones para nombrar a regidores honorarios y síndicos personeros del común. Los reconoce como los representantes de los intereses de los vecinos; sin embargo, da cuenta que los pocos estudios que existen no son claros en cuanto a la manera de nombrarlos. François-Xavier Guerra, citado por Rodríguez (2005), afirmó que los ayuntamientos novohispanos contaban con diputados y síndicos personeros del común elegidos por todos los vecinos.

${ }^{13}$ Expediente formado sobre la erección de regidores honorarios en la forma que dentro se expresa. 1770. Fondo Ayuntamiento. Sección Regidores honorarios. Vol. 412, exp. 1, 92 fs. AHDF, México.

${ }^{14}$ Expediente formado sobre la erección de regidores honorarios en la forma que dentro se expresa. 1770. Fondo Ayuntamiento. Sección Regidores honorarios. Vol. 412, exp. 1, f. 5. AHDF, México.

${ }^{15}$ Expediente formado sobre la erección de regidores honorarios en la forma que dentro se expresa, 1770. Fondo Ayuntamiento. Sección Regidores honorarios. Vol. 412, exp. 1, f. 4. AHDF, México.

\section{()(1) $\$$}


La evidencia documental permite afirmar que la implementación de esta reforma, al menos en el caso del Cabildo de la ciudad de México, no tuvo las mismas características en su elección. Los cargos de regidores honorarios no fueron reflejo de los deseos de los habitantes de la ciudad que los eligieron mediante un voto, sino que fueron elegidos directamente por el virrey sin intervenir otro funcionario. Estos cargos, aunque fueron establecidos con la intención de dividir las funciones concejiles y vigilar los intereses del rey, no surgieron de una elección indirecta.

El virrey Carlos Francisco de Croix designó a los regidores honorarios del Cabildo de la ciudad de México, por lo cual se les denominaba "regidores honorarios electivos", por ser seleccionados dentro de una terna y sin que intervinieran electores indirectos como en Madrid. ${ }^{16} \mathrm{El}$ establecimiento de estos regidores, al menos en el caso del Cabildo de la ciudad de México, no fue una prueba de las nuevas ideas políticas de representación del individuo en su colectividad, pues fue una decisión tomada desde el gobierno virreinal y recibieron la anuencia real. La discusión de los regidores no ocurrió por la manera en que serían seleccionados, sino por la forma en que participarían en el Cabildo: el lugar de su asiento, las ceremonias que se le habían de hacer, los privilegios que obtendrían de dicho cargo y de la jurisdicción que tenían en los asuntos de interés del regimiento.

Los primeros regidores honorarios fueron presentados por Areche y confirmados por el virrey Croix. Estos eran el conde de San Mateo de Valparaíso, el mariscal de Castilla, el marqués de Rivascacho, Francisco Sánchez de Tagle, Ambrosio de Meave y Juan de Castañiza, siendo este último el que ejercería el cargo de procurador general del común, también conocido como síndico del común. José Antonio de Areche solicitó al Concejo instruyera a los nuevos regidores en sus oficios y solicitó al corregidor llamase a los cabildos ordinarios y extraordinarios necesarios para que los regidores que cumplieran con alguna comisión demostrasen las tareas realizadas "sin que se pueda esperar la excusa de los caballeros regidores con que se les imponga la pequeña pena de la ordenanza". ${ }^{17}$

${ }^{16}$ Testimonio de la instancia de la N. C. de México, sobre exonerarse de la visita subdelegada al señor D. José Antonio de Areche. 1768. Instituciones coloniales. Ayuntamiento. Contenedor 72, vol. 210, exp. 1, fs. 3v-4. AGN, México.

17 Testimonio de la instancia de la N. C. de México, sobre exonerarse de la visita subdelegada al señor D. José Antonio de Areche. 1768. Instituciones coloniales. Ayuntamiento. Contenedor 72, vol. 210, exp. 1, fs. 3v-4. AGN, México.

\section{(ㅇ)(1) 3}


La instrucción daba a los regidores honorarios facultades para "tratar y conferir en punto de abasto y propuestas que se hicieran para beneficio del bien común", con la intención de allanar el camino hacia una nueva reglamentación del consumo de maíz y del gremio de panaderos. Los regidores honorarios podían estar presentes en las juntas del pósito y otras concernientes al abasto de pan para que reconocieran su calidad, precio y peso, de la misma manera que el síndico del común. Debían asistir a la mesa de propios y junto con el juez superintendente, poner en orden las cuentas de propios $y$ arbitrios de la ciudad de México. ${ }^{18}$ No obstante, los regidores perpetuos no permitieron que los honorarios pudieran votar en las juntas, ni realizar labores como vigilancia del peso del pan, visitas como fieles ejecutores a las tiendas de la ciudad, control del abasto de carne, etc., debido a que consideraban que la novedad de estos cargos implicaba un desconocimiento total de las tareas de un regidor, además señalaban que los regidores honorarios tenían como única facultad, opinar.

El reglamento sobre regidores honorarios señalaba que no debían percibir sueldo ni ejercer más función que las de carácter meramente consultivo, emulando así el sistema vigente en Madrid, lo que permitía la estrecha vigilancia del organismo central sobre las funciones del regimiento. ${ }^{19} \mathrm{El} \mathrm{fiscal}$ Areche señalaba que los regidores honorarios debían tener las mismas facultades que los regidores perpetuos, pues no debían existir diferencias odiosas que impidieran ver a los regidores honorarios como extraños al Cabildo, por lo cual debían sentarse uno junto al otro a partir del asiento del corregidor. Sin embargo, el Cabildo sostuvo su posición de evitar la ignorancia de la antigüedad de sus integrantes y consiguió que dicha alternancia de lugares fuera a partir del regidor decano, por lo cual quedaban al frente el corregidor, los alcaldes ordinarios o mayores y el regidor decano. ${ }^{20}$

En 1771, cuando regresó Gálvez de su visita en las Provincias Internas, se creó el Reglamento de Propios y Arbitrios de la Ciudad de México y se logró establecer las condiciones sobre las cuales debería empezar a trabajar

${ }_{18}$ Testimonio de la instancia de la N. C. de México, sobre exonerarse de la visita subdelegada al señor D. José Antonio de Areche. 1768. Instituciones coloniales. Ayuntamiento. Contenedor 72, vol. 210, exp. 1, fs. 3v-4. AGN, México.

${ }^{19}$ Actas de Cabildo originales de sesiones ordinarias 1770. Fondo Ayuntamiento. Gobierno del Distrito Federal. Sección Ayuntamiento. Vol. 90-A. AHDF, México.

${ }^{20}$ Expediente formado sobre la erección de regidores honorarios en la forma que dentro se expresa. 1770. Fondo Ayuntamiento. Sección Regidores honorarios. Vol. 412, exp. 1, f. 5. AHDF, México.

\section{()(1) $\$$}


la Contaduría General, con la cual se buscaba una vía más para enfrentar el déficit real al hacer uso de esos recursos. En 1773 el Cabildo logró que el rey les permitiera designar a tres de los regidores honorarios de entre sus integrantes, los cuales ya tendrían voto y podrían participar en las tareas del Cabildo. ${ }^{21}$ De esta manera el Ayuntamiento recuperaba su control en la administración de la ciudad y en las actividades que correspondían al diputado del común. Su preeminencia como corporación representante de la ciudad no fue lastimada, y los fueros de que gozaban los regidores no se ampliaron a personas no involucradas en la organización de la ciudad. ${ }^{22}$ Así, para 1786 ya no había una clara diferencia entre regidores perpetuos o también llamados ordinarios y regidores honorarios o electivos, así que los regidores pudieron designar sin demasiada cautela los asuntos en los que podían intervenir los regidores honorarios y se rolaba el cargo de manera bianual.

\section{LA ORGANIZACIÓN ADMINISTRATIVA DEL AYUNTAMIENTO CON LA ORDENANZA DE INTENDENTES}

A partir de la Ordenanza de Intendentes de 1786 los corregidores-intendentes como presidentes del Concejo fueron un vínculo entre los virreyes y los concejales. Los corregidores-intendentes eran los interlocutores de los deseos del virrey, y debían velar que dichas disposiciones se llevaran a cabo. ${ }^{23}$ Dentro del Ayuntamiento, la Ordenanza de Intendentes trajo como consecuencia una nueva distribución en la estructura organizativa de las tareas del Cabildo al crear juntas internas, quienes tendrían la tarea de controlar el buen

${ }^{21}$ Expediente formado sobre la erección de regidores honorarios en la forma que dentro se expresa. 1770. Fondo Ayuntamiento. Sección Regidores honorarios. Vol. 412, exp. 1, f. 5. AHDF, México.

${ }^{22}$ Expediente formado sobre la erección de regidores honorarios en la forma que dentro se expresa. 1770. Fondo Ayuntamiento. Sección Regidores honorarios. Vol. 412, exp. 1, f. 5. AHDF, México.

${ }^{23}$ José Ignacio Ruiz Calado, asesor ordinario de la Intendencia General de Ejército y Provincia de la ciudad de México, y de la Superintendencia General Subdelegada de Real Hacienda de Nueva España. Era un asesor letrado, abogado de la Real Audiencia, el cual debía vigilar "la más pronta y segura administración de Justicia". La cantidad de trabajos a su cargo como oidor de la Real Audiencia puede ayudar a explicar que difícilmente se hallaba en las juntas del Cabildo. Actas de Cabildo de sesiones ordinarias. 1787. Fondo Ayuntamiento. Gobierno del Distrito Federal. Sección Ayuntamiento. Vol. 107-A. AHDF, México.

\section{(ㅇ)(1) $\$$}


funcionamiento de la ciudad en materias concretas, como limpieza de calles, orden de la ciudad y abasto seguro de alimentos a sus habitantes.

La creación de oficios dentro del Cabildo con la Ordenanza de Intendentes supuso una mayor definición de facultades, desaparecieron oficios concejiles en tareas que se consideraban semejantes para ser tratados por un solo funcionario y se crearon otros cargos con la intención de reunir en un solo individuo tareas afines lo que llevó a una especialización de las tareas de los regidores quienes debían tener una línea de autoridad hacia la centralización.

Se crearon "tribunales", que fueron pequeñas oficinas que reagrupaban y dividían por materias las tareas del cabildo, para que se encargaran de asuntos particulares. Así, la Junta Municipal de Propios y Arbitrios, la Junta de Policía, la Junta de Abasto y Fiel Ejecutoria se convirtieron en pequeñas cámaras con un juez y sus respectivos diputados (regidores delegados para vigilar materias específicas propias del cabildo). Cada uno de los jueces de su Junta debía llevar bastón de justicia. Sin embargo, en las Juntas en las que el corregidor fungía como juez, por ejemplo la Junta de Gremios, la Junta de Pósito y Alhóndiga y la Junta de Policía, los regidores mantuvieron la costumbre de llevar el bastón de justicia más como un símbolo de su cargo, tal era el caso del juez fiel ejecutor, el juez de plaza, los jueces de arquerías, cañerías, ríos, sitios y ejido. ${ }^{24}$

La consolidación de las reformas borbónicas en Nueva España fue el establecimiento de intendencias. El plan de reformas llevado a cabo por los Borbones y sus ministros en sus posesiones americanas fue intervenir paulatinamente en el gobierno local para disminuir su fuerza política, sin menoscabo de los fueros y privilegios otorgados por sus antecesores evitándose así una ruptura entre las ciudades y el monarca, sino creándose oficiales que vigilaran más cercanamente la administración concejil y mantuvieran firmemente su lealtad al rey. En el ámbito administrativo fue necesario disminuir las facultades de las distintas corporaciones, mismas que habían adquirido dos importantes distinciones: legislar y castigar a sus integrantes, así como manejar sus propios fondos económicos. Hasta antes de las reformas, estas dos tareas quitaban al monarca su capacidad como juez universal y contro-

${ }^{24}$ Cedulario pasta española. Fondo Ayuntamiento. Gobierno del Distrito Federal. Sección Ayuntamiento. Vol. II, exp. 3. AHDF, México. Compárense el esquema 1 y el cuadro 1.

\section{(ㅇ)(1) $\$$}




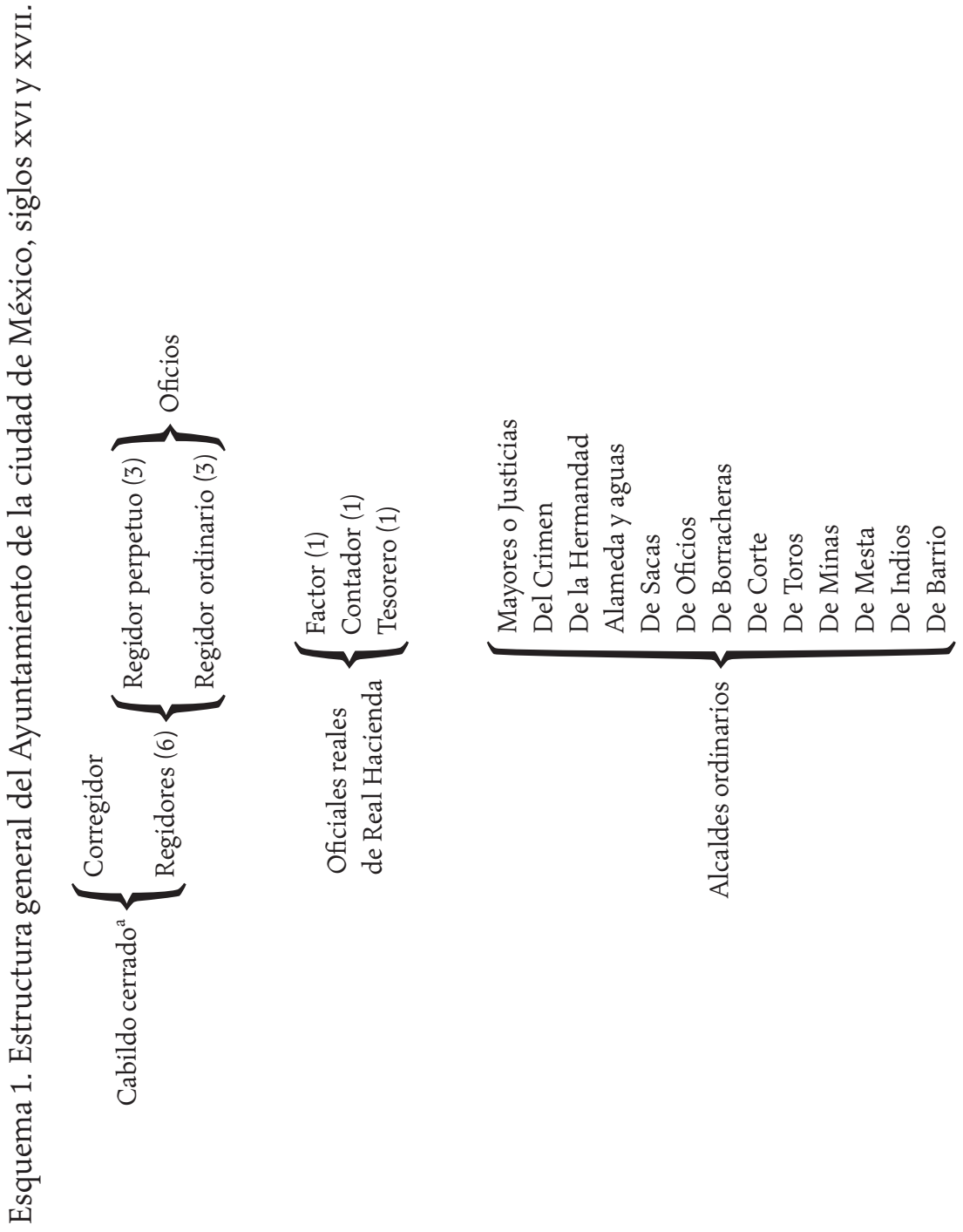

(c) (1)\$ 

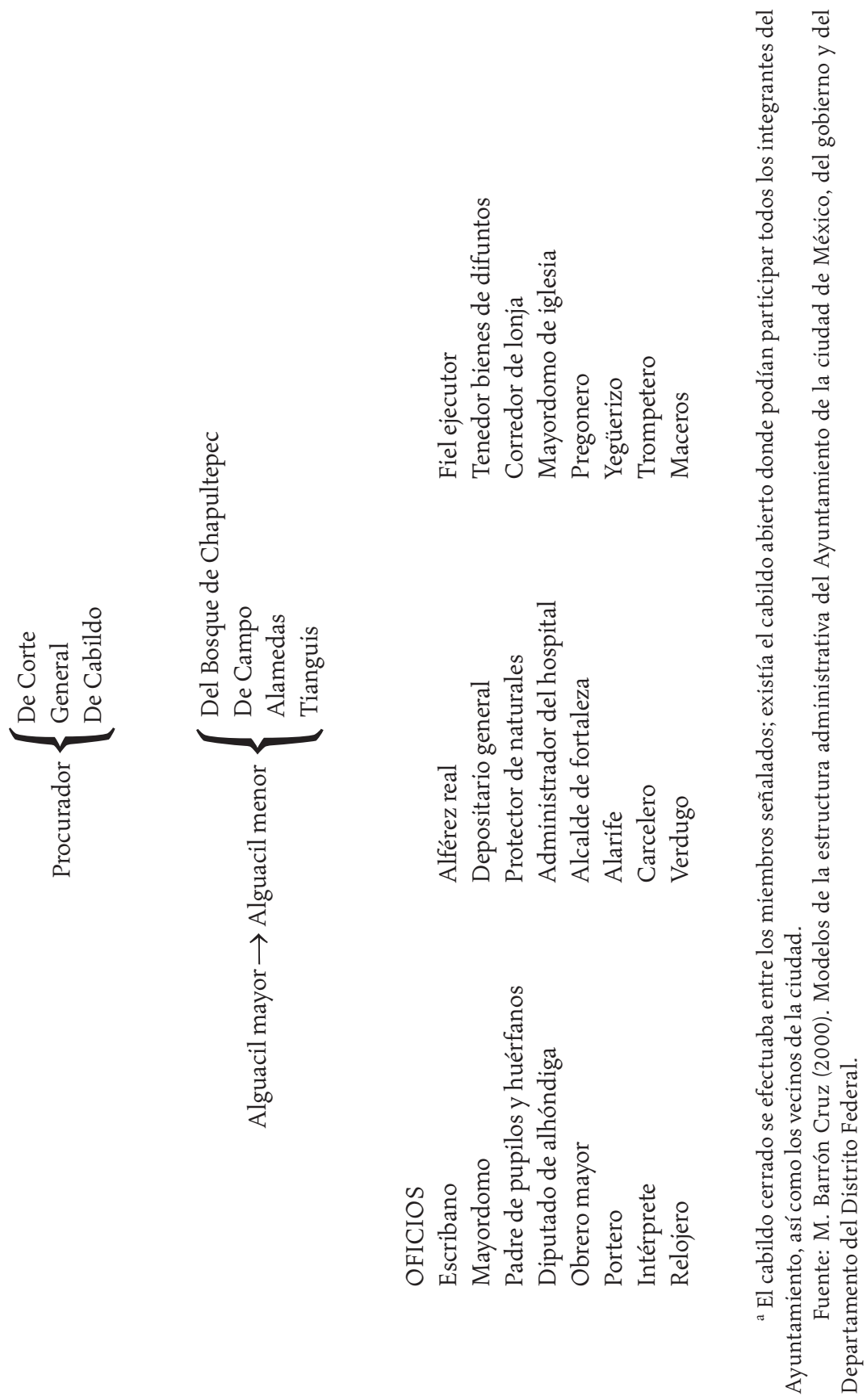

\section{(ㅇ)(1) $(3$}



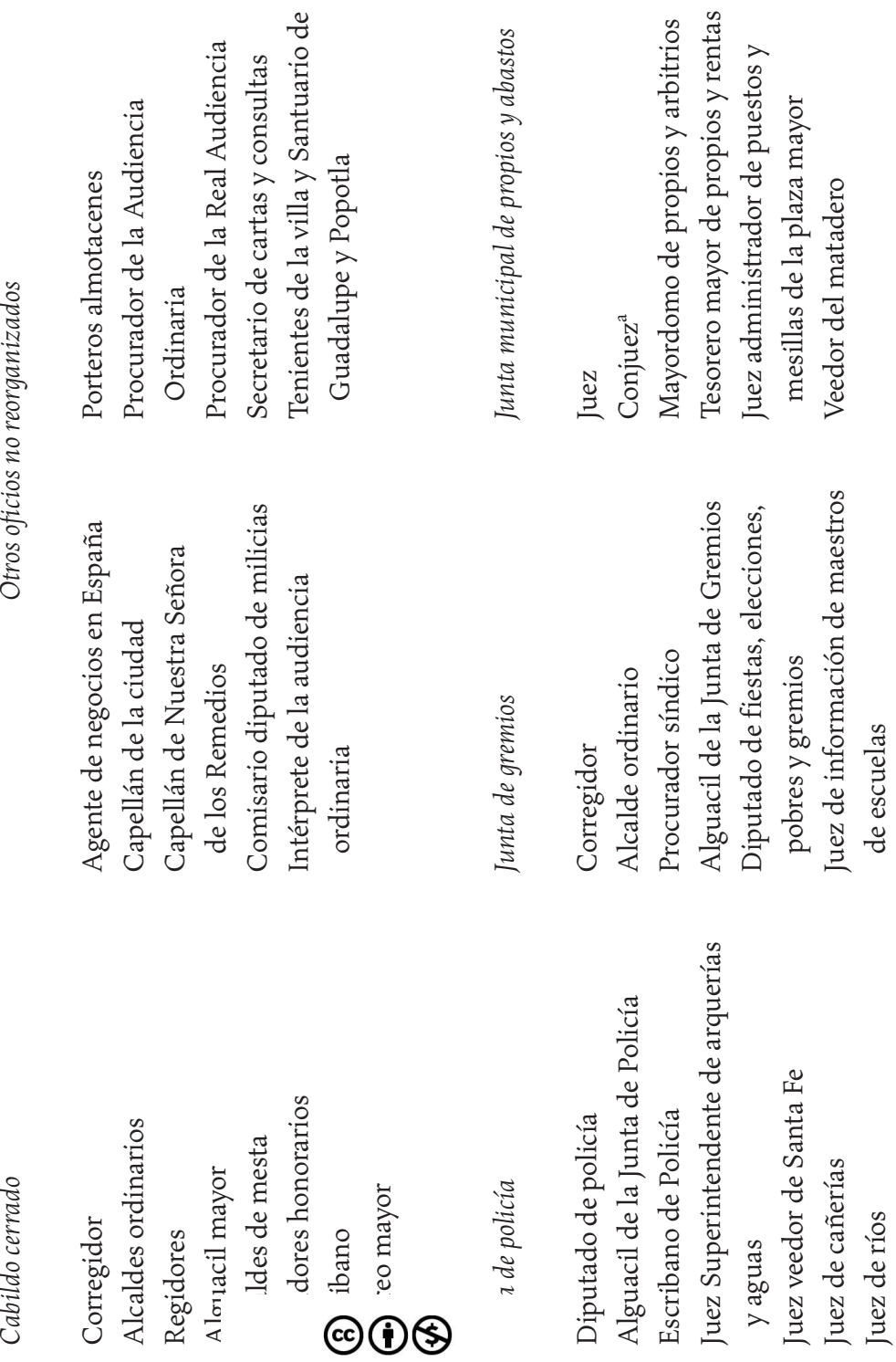

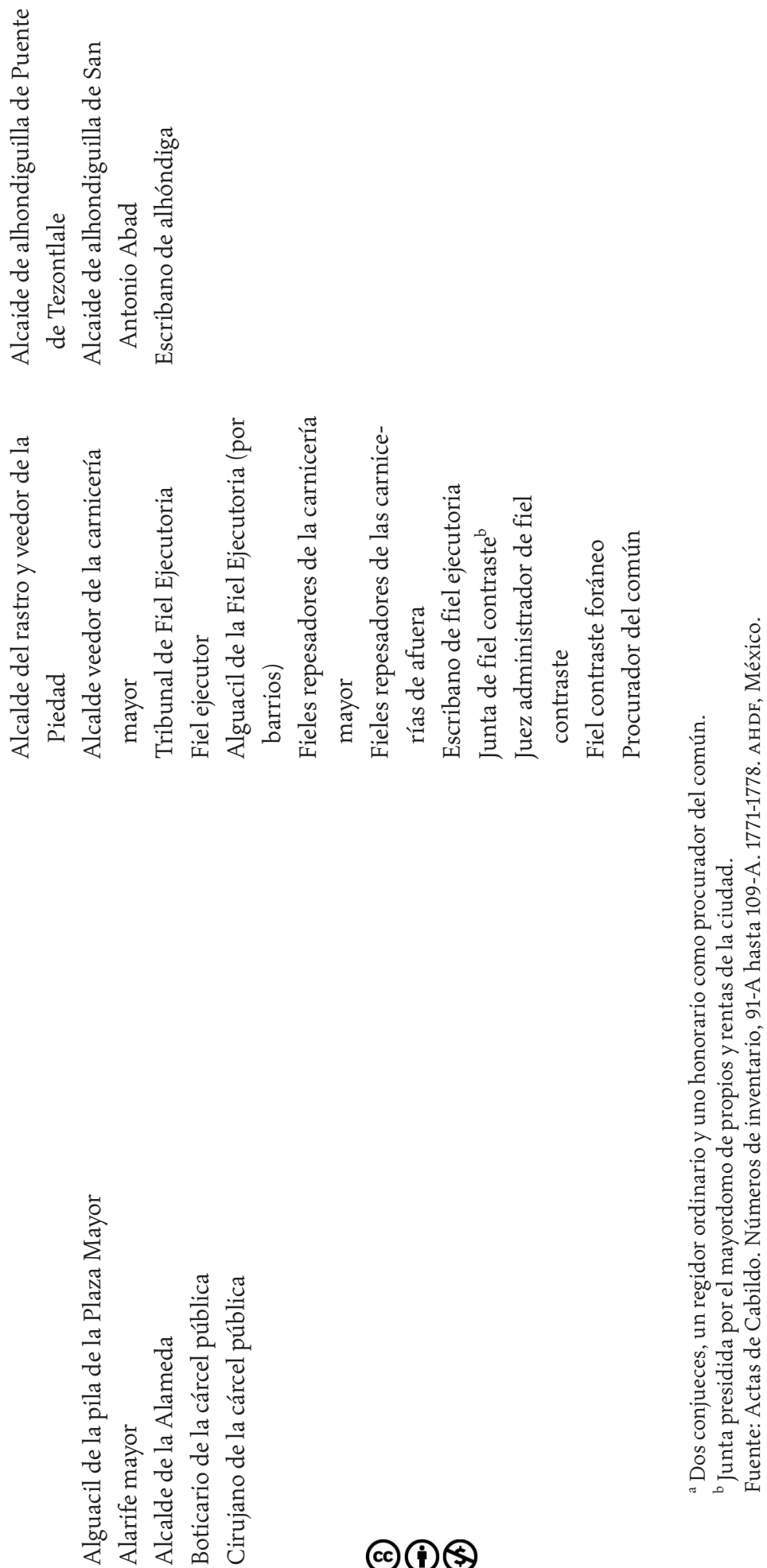
lador de la paz de su reino, y lo dejaba ciego en relación con los frutos que generaban sus propiedades.

Una vez que las reformas al Cabildo fueron realizadas, las intendencias reglamentaron oficialmente y para toda Nueva España las disposiciones que poco a poco se habían realizado antes de 1786. La creación de Juntas Municipales de Propios, Arbitrios y Bienes de Comunidad, supeditadas a la Junta Superior de Real Hacienda, fueron la consolidación de la orden para realizar reglamentos particulares por ciudad sobre las entradas en forma de propios y arbitrios, así como los gastos concejiles. Por otra parte, en el caso de los regidores honorarios, la ordenanza sólo señalaba que se mantuvieran como hasta ese momento se encontraban, tanto en número como en su manera de elección, lo que refleja la preocupación de la corona por mantener una relación estrecha con sus ciudades. Si el rey no hubiera permitido la presencia de criollos en el gobierno de la ciudad no se llevaría a cabo uno de los elementos del Cabildo que era considerarlo como el representante de los vecinos. Sin embargo, la corona logró intervenir en las decisiones del Ayuntamiento al incluir dentro del Concejo a personas, no necesariamente españoles peninsulares, allegadas a su gobierno.

\section{EL PRIMER IMPACTO CONSTITUCIONAL GADITANO}

Las Cortes extraordinarias creadas debido a la falta de rey desde 1808, lograron plasmar sus esfuerzos en la Constitución Política de la Monarquía Española, la cual fue promulgada en Cádiz el 19 de marzo de 1812 y jurada en la capital de Nueva España el 30 de septiembre del mismo año. ${ }^{25} \mathrm{~A}$ través del Real Decreto de las Cortes del 23 de mayo de 1812, se ordenó la creación de los ayuntamientos constitucionales, lo que hizo en Nueva España el virrey Francisco Xavier Venegas el 15 de octubre del mismo año. Días después, el virrey solicitó al intendente Ramón Gutiérrez del Mazo que convocara y presidiera las juntas electorales para elegir alcaldes, regidores y procuradores síndicos, quienes entrarían en función a partir del 1 de enero de $1813 .^{26}$

${ }^{25}$ Ayuntamiento del 19 de octubre y 3 de noviembre de 1812. Fondo Ayuntamiento. Gobierno del Distrito Federal. Sección Actas de Cabildo de sesiones ordinarias. Vol. 131-a, 1812. AHDF, México.

${ }^{26}$ Representación al Supremo Congreso sobre la omisión de este gobierno en instalar la Diputación Provisional y habilitar a los diputados para las próximas Cortes. 1813. Fondo

\section{(ㅇ)(1) $\$$}


Las elecciones para los ayuntamientos constitucionales fueron, según Virginia Guedea (1992), el espacio donde confluyeron las simpatías por los insurgentes y la lucha de los peninsulares por mantenerse en el escenario político. ${ }^{27}$ Aun cuando para el grueso de la población criolla fue un triunfo la llegada de nuevos elementos en el Cabildo de la ciudad de México, los regidores perpetuos se mantuvieron en su oficio, pues aunque estaban dispuestos a dejar sus cargos -la cual era una disposición del rey a través de la Junta de Regencia-solicitaban que se les devolviera el pago que hicieron por sus puestos, amparándose en el artículo 171 de la misma Constitución gaditana que señalaba:

"No puede el Rey tomar la propiedad de ningún particular ni corporación, ni turbarle en la porción, uso y aprovechamiento de ella, sin que al mismo tiempo sea indemnizado y se le dé el buen cambio a vista de hombres buenos" así que consideraban su indemnización como un derecho. Además pedían el pago de los sueldos y ayudas de costas de las comisiones que les eran propias a su cargo, ya que era "justo [...] repararles hasta el último cuadrante del demérito que les causa [la] expulsión de sus empleos". ${ }^{28}$

Es decir, reclamaban todo lo invertido en el Cabildo y el pago de las deudas que dicha corporación había adquirido con ellos. Esta era una petición difícil de cubrir, pues la crisis económica de la monarquía española era evidente, además no había a quién cobrarle. Ante tal situación, acordaron solicitar que mientras se cubrían sus peticiones pudieran gozar de sus sueldos, uniformes y todas las facultades que le fueron conferidas al comprar sus títulos. Se puede suponer que en el Ayuntamiento constitucional confluían dos posturas: los que consideraban su puesto como una propiedad y aquellos que lo veían como una delegación de poder de los vecinos. Esta ambigüedad del primer Cabildo constitucional se presume como el espejo de lo que

Ayuntamiento. Gobierno del Distrito Federal. Sección Historia en general. Vol. 2254, exp. 69, 7 fojas, 2 bandos. AHDF, México.

${ }^{27}$ La autora menciona que este hecho fue aprovechado por grupos proinsurgentes como los "Guadalupes" para alcanzar puestos públicos con los que derrocar el gobierno español.

${ }^{28}$ Representación dirigida al Superior Gobierno pidiendo se reembolse a los regidores el valor de sus empleos y gastos que erogaron para obtenerlos y que entretanto se les atienda con sus sueldos y continúen disfrutando sus honores para indemnizarles la pérdida de dichos empleos que fueron extinguidos por la Constitución española de 1812. 1812. Fondo Ayuntamiento. Gobierno del Distrito Federal. Sección Ayuntamiento. Vol. 395, exp. 130, 6 fojas. AHDF, México.

\section{()(1) $\$$}


ocurría dentro de la ciudad de México, ya que contaba con instituciones de antiguo régimen que debían interactuar con el mejor ejemplo en ciernes del liberalismo, es decir, un gobierno electo.

Francisco Xavier Venegas intentó postergar la aplicación de la Constitución, ya que no estaba a favor de los cambios que con esta acta se llevarían a cabo. Fue hasta que Félix María Calleja tomó el cargo de virrey que mandó, a su pesar, jurar la carta gaditana. ${ }^{29}$ Calleja quedaba como la suprema autoridad del reino, con todos los poderes para determinar lo que considerara necesario para su mantenimiento; a esto hay que agregar su antigaditanismo y su recelo al liberalismo que promovían los constitucionalistas ya que, según el virrey, la carta gaditana ponía en peligro su autoridad y promovía la insurgencia. Ante esto, los nuevos regidores se enfrentaron con una autoridad poco flexible a permitirles realizar las tareas para las que habían sido seleccionados, ya que la existencia de un Ayuntamiento constitucional contrastaba con la permanencia del virrey en el gobierno.

A dos meses de la instalación del Ayuntamiento constitucional, el virrey Calleja ordenó al Cabildo que enviara una lista de los principales sujetos de la capital que simpatizaban con la insurgencia. Entre estos se encontraban electores como José María Alcalá, canónigo de la catedral, Jacobo de Villaurrutia (oidor de la Real Audiencia) y Carlos María de Bustamante, así como algunos de los nuevos integrantes del Concejo de la ciudad. El Cabildo se negó a enviarla por lo que aumentaron las reticencias de Calleja a este órgano (Guedea, 1992, p. 194). ${ }^{30}$ El virrey puso en tela de juicio la representatividad del nuevo Ayuntamiento y una manera de hacer público su desagrado fue apropiándose de sus tareas, tal como ocurrió con la creación de la Junta de Policía. Calleja intentó restarle importancia a aquellos que creía eran integrantes de la insurgencia y representantes del nuevo sistema de gobierno por lo que desairaba las invitaciones a las ceremonias públicas convocadas por el Cabildo (Sánchez, 2007, pp. 247-274).

${ }^{29}$ Aunque la Constitución abolió las funciones del virrey y le quitó el control de los asuntos de la capital, en Nueva España se mantuvo dicho cargo como una manera de control ante el peligro que significaba el movimiento insurgente iniciado en 1810 pues desde los sucesos ocurridos en Bayona en varias ciudades de América ya se había declarado la independencia; sólo quedaban Perú y Nueva España como posesiones españolas.

${ }^{30}$ La relación de algunos de los regidores con los insurgentes a través de la asociación conocida como los Guadalupes fue probada cuando toda la correspondencia de este grupo con Morelos cayó en manos de los realistas en Tlacotepec en 1814. En este conjunto de cartas se especificaban las maneras en que algunos de los integrantes del Concejo -por ejemplo Francisco Manuel Sánchez de Tagle e Ignacio Adalid-ayudaban a los insurgentes.

\section{(ㅇ)(1) $\$$}




\section{LAS REPERCUSIONES DE LA \\ CONSTITUCIÓN DE CÁDIZ EN LA ESTRUCTURA Y LAS FUNCIONES DEL AYUNTAMIENTO DE LA CIUDAD DE MÉXICO}

Con la promulgación de la carta gaditana, la facultad de crear ayuntamientos dejó de ser un privilegio real para convertirse en un derecho de las ciudades que contaran con una población mayor a 1000 habitantes, pero siempre supeditados a la autoridad de las Cortes y de las Diputaciones Provinciales. En 1813 se constituyó el Ayuntamiento constitucional en la ciudad de México. Para realizar las tareas que la carta gaditana señalaba, se reorganizó el Cabildo en comisiones. Esta forma de organización político-administrativa estaba orientada a una nueva noción de los encargos, que se concibieron como temporales y no como una posesión del oficio, tal y como los anteriores regidores lo hicieron. Es decir, debido a que los regidores constitucionales ya no eran dueños del cargo, tampoco estaban en posesión de alguna facultad específica permanente (Mannori y Sordi, 2004, p. 74). Con esto se concretó el proyecto absolutista de disminuir la capacidad jurídica del Cabildo, ya que su tarea quedó acotada a sólo regular y sin la facultad de dictar sentencia debido a que se debían ceñir a un cuerpo legislativo más grande como la Constitución (Fernández, 1993, pp. 284-299).

En cuanto a las funciones, la idea era continuar con el proyecto de redefinición de estas y el control de los funcionarios. Los diputados de Cádiz de ninguna manera proyectaron una mayor autoridad para los cabildos, por que se temía llegar a la federalización (Hijano, 1996). Para realizar con acierto esa nueva organización administrativa se tuvieron que examinar los encargos antiguos para equipararlos con los nuevos comprendidos en cada uno de los artículos expedidos por la carta gaditana. ${ }^{31}$ Se tuvieron que dividir las funciones del Ayuntamiento tomando como referencia el origen de la materia. Por ejemplo, dentro de la policía de la ciudad, a la que se entendía como el buen orden de ella y de la comodidad de sus habitantes, se encontraban las tareas de vigilancia del abasto y limpieza de las calles (Ohgaki, 1979, p. 90). Si se compara esta nueva estructura administrativa en comisiones con la que se tenía en juntas, se notará que las funciones no variaron, ya que estaba a cargo

${ }^{31}$ Plan de las Comisiones de esta N. C. repartidas entre los individuos de su Ayuntamiento remitido a su excelencia y oficio de su aprobación. 1813. Fondo Ayuntamiento. Gobierno del Distrito Federal. Sección Comisiones. Vol. 406, exp. 10, 4 fojas. AHDF, México.

\section{(이요 $\$$}


del Cabildo mantener el orden y salubridad de la cuidad, la administración e inversión de los propios y arbitrios conforme a las normas establecidas por el gobierno general, la recaudación de contribuciones para remitirlos a la tesorería respectiva, mantener y cuidar las escuelas de primeras letras, cuidar los hospitales. En resumen, el Ayuntamiento continuó con las tareas de administración urbana, es decir, el proyecto de separar el "gobierno político" del "gobierno jurídico" se mantuvo vigente pues resultaba útil para los intereses de los legisladores gaditanos (Bonnin, 2003; González, 1995) (compárense el esquema 1 y el cuadro 1 ).

Los regidores constitucionales tomaron como referencia para organizar sus ocupaciones el artículo 321 del capítulo I, título vi de la Constitución Política de la Monarquía Española. Los incisos que integraron dicho artículo definieron las tareas del Ayuntamiento y muestran que se otorgó mayor acento a la regulación de los fondos del Cabildo, además que se generalizaron las tareas que en la época se llamaban de "policía". ${ }^{32}$ Sobre la primera comisión de la salubridad y la comodidad pública, resulta complicado definir a qué se refería este encargo debido a que en él se involucraba la higiene y seguridad de los distintos espacios de la ciudad. Sin embargo, se puede señalar por ahora que tenemos dos asuntos. El primero es la salubridad, a la que se entiende como higiene pública; de acuerdo con esto en ella se pueden agrupar el aseo de la ciudad, teatros, paseos y diversiones públicas, arreglo de mercados y alimentos (en su estructura física y limpieza). En cuanto a la comodidad pública, que implicaba buena movilidad dentro de la ciudad, tenemos los servicios de empedrados y banquetas, desembarazo de calles y tránsito, alumbrado, coches de alquiler, arreglo de los edificios (evitar fincas ruinosas que le quitaban belleza a la ciudad) y vigilancia de las fiestas para evitar desórdenes, esta comisión tiene estrecha relación con la Junta de Policía creada con la Ordenanza de Intendentes.

En la segunda comisión, sobre la seguridad de las personas y bienestar de los vecinos, así como la conservación del orden público, en primer lugar hay que señalar que mencionan "la seguridad de las personas" para referirse a los individuos, y "bienestar de los vecinos" para referirse a los habitantes de la ciudad. Dentro del bienestar de las personas se encuentra las rondas de vigilancia para evitar algún daño a la integridad física de los individuos. En cambio, al referirse al bienestar de los vecinos se encontraba la revisión

32 Constitución Política de la Monarquía Española, capítulo II, artículos 324 a 337 (en Hernández y Dávalos, 2006, vol. IV, docto. 40.)

\section{()(1) $\$$}


de pesos y medidas porque a través de esta tarea se procuraba evitar el daño ocasionado a la comunidad al sufrir algún fraude al recibir mercancía mal pesada. En ambos casos, al darle seguridad y abasto seguro, el Ayuntamiento procuraba mantener el orden público. Su correlato con los tribunales se puede encontrar en las tareas de la Junta de Fiel Contraste, así como en la Junta de Policía.

La tercera y cuarta comisiones muestran la separación y cuidado que se tuvo en las tareas de la Junta Municipal de Propios, Arbitrios y Abastos, ya que se organizaron grupos para que administraran los fondos del Cabildo de acuerdo con la ley, y por otra parte para tener mayor control de las contribuciones que enviaban a la tesorería de la ciudad de México. En 1806 se creó la Junta de Caridad y Hospicio de Pobres, en la que se encontraba un médico cirujano, el boticario y el diputado de pobres y gremios. Esta junta se puede considerar el antecedente de la comisión sexta otorgada a los ayuntamientos con la Constitución de 1812. En cuanto a la comisión número siete, se refiere a las tareas que tenía la anterior Junta de Policía. Tanto la octava como la novena comisiones eran una novedad porque eran actividades propias del corregidor, los alcaldes ordinarios y los regidores y a partir de entonces tendría que ser indistinto el cargo de los encargados de esta tarea. Igual de novedosa era la tarea de promover la agricultura, la industria y el comercio, pues si bien era una tarea del concejo no se había determinado una junta para tal efecto.

Mientras se discutía la Constitución en Cádiz, los regidores se enfrentaban con una nueva forma de gobierno, y cuestionaban al virrey sobre algunos elementos de preeminencia, por ejemplo: los regidores trataban de evitar que el virrey interviniera en la definición de las tareas argumentando que se violaba el secreto de las juntas si se le entregaba una relación de los votos para definir los cargos del Cabildo. Asimismo, al interior del Ayuntamiento los regidores debatían si los regidores constitucionales podían usar el bastón que los distinguía como regidores, el asunto tenía de fondo que ese bastón los evidenciaba como los encargados de la "jurisdicción contenciosa", pero con la Constitución ya no gozaban de esa facultad. La discusión entre los regidores era que el bastón servía como un distintivo para ser identificados por el pueblo, otros que la Constitución ponía en manos de los ayuntamientos el gobierno de los pueblos (artículo 309) especificando más extensamente esta idea en el artículo 321, y que no podía haber gobierno sin alguna clase de jurisdicción y les parecía que no podían carecer de ella los ayuntamientos. El intendente Gutiérrez del Mazo señalaba que el uso del bastón tenía que ver con el pago de la media anata para ejercer el cargo, cosa que ya no realizaron

\section{(1)(1) $\$$}


los regidores electos; finalmente y fundamentando su resolución con base en la costumbre que tenían los habitantes de ver al regidor con bastón, se decidieron por usarlo. ${ }^{33}$

Luego de la publicación de la Constitución, se difundió el 23 de mayo de 1812 en Cádiz el decreto para la "Formación de los ayuntamientos constitucionales". Este decreto tenía la intención de uniformar los huecos legales y las vacilaciones interpretativas sobre tres puntos, a saber: los lugares que no contaran con más de 1000 almas y desearan formar ayuntamientos; el cese de cargos de antiguo régimen y la manera de nombrar a los nuevos funcionarios $y$, por último, la conformación de las juntas de parroquia y el número de electores que las constituirían.

Varios días después, la Comisión de Constitución de las Cortes presentó un texto para detallar las atribuciones de los ayuntamientos y las diputaciones provinciales. La "Instrucción para el gobierno económico y político de las provincias" fue presentada a las Cortes el 21 de mayo de 1813 y no mereció mayores debates ya que tan sólo propuso matices o pequeñas adiciones al texto original. Así que fue expedida en Cádiz, el 23 de julio de 1813 (Chust, 2007, pp. 41-43).

De acuerdo con la documentación analizada, dicha instrucción no logró ejecutarse en la ciudad de México, al menos no hay alguna referencia a ella en las actas de Cabildo o algún otro expediente en el transcurso del primer Ayuntamiento constitucional. Un ejemplo claro puede ser que la instrucción mencionaba como fecha para la elección de nuevos regidores constitucionales el 24 de septiembre de 1814, pero no se realizó ya que las noticias sobre el regreso al trono español de Fernando VII llegaron a Nueva España en agosto del mismo año. Es de subrayar que se hace alusión a ella en 1821 y 1822, cuando la regencia la retomó para reglamentar la relación entre los ayuntamientos, los jefes políticos y la Diputación Provincial. ${ }^{34}$ Posteriormente, según Ariel Rodríguez Kuri (1994, pp. 53-54), se tomó como referencia para delimitar las funciones del gobernador del Distrito Federal y para formar

${ }^{33}$ Sesión de Cabildo. 1813. Fondo Ayuntamiento. Gobierno del Distrito Federal. Sección Actas de Cabildo originales de sesiones ordinarias. Vol.132-A, fs. 70-74v. AHDF, México.

${ }^{34}$ El Soberano Congreso Constituyente decretó se aplique la observancia del artículo 17, capítulo 2 de la Instrucción para el Gobierno Económico Político de las Provincias dado por las Cortes españolas, por el cual se establece que los ayuntamientos y diputaciones provinciales se comuniquen con el gobierno y este con ellas por medio de los jefes políticos. Junio, 1822. Fondo Municipalidades. Sección San Ángel. Serie Bandos. Caja 1, exp. 12. AHDF, México.

\section{(ㅇ)(1) $\$$}


las ordenanzas municipales de 1840; estas últimas estuvieron vigentes -con algunas modificaciones- hasta 1903.

\section{CONCLUSIONES}

Las reformas giradas por Carlos III durante la década de los sesenta del siglo XVIII fueron expresión de la política ilustrada, en la cual el rey intentaba controlar sus dominios en todos los niveles de gobierno. Al crear cargos que tuvieran un vínculo más fuerte con el soberano se intentaba disminuir las facultades de la corporación que representaba a la ciudad. Con la creación de la Contaduría General de Propios, Arbitrios y Bienes de Comunidad del Reino de la Nueva España se determinaba la formación de una instancia reguladora y fiscalizadora de las rentas locales, a imagen y semejanza de la impuesta en España. La instrucción preparaba el camino hacia una administración directa de las rentas concejiles por parte de funcionarios reales cuyo propósito fue acabar con los arrendamientos del cobro de impuestos locales y manejar los fondos del Ayuntamiento, lo cual menguaría a la postre el poder que los ayuntamientos habían detentado por tantos años (Guillamón, 1980, p. 187-194).

La designación de regidores honorarios, al menos en el caso del Cabildo de la ciudad de México, no tuvo las mismas características que en España, pues en la ciudad de México no fueron un reflejo de los deseos de los habitantes de la ciudad que los eligieron mediante un voto, sino que fueron seleccionados directamente por el virrey sin intervenir otro funcionario.

Los nuevos empleados sabían que había que atacar los excesos de los cabildos, como no asistir a las juntas o no obedecer las disposiciones reales. Los nuevos burócratas que trataban de introducir nuevos esquemas de organización se enfrentaron con una corporación que basaba su funcionamiento y presencia política en fueros y privilegios con los cuales justificaban y defendían su labor dentro del Ayuntamiento de la ciudad de México.

Las diferencias con España se pueden encontrar en las posiciones tomadas por los ayuntamientos novohispanos ante un grupo de reformas que atacaron sus intereses, si se toman en cuenta las reacciones se podrá comprender por qué tardaron en realizarse los reglamentos particulares. Un contraste significativo entre España y Nueva España fue el objetivo de la puesta en marcha de estas reformas. Mientras que en la península fue desde el inicio del siglo XVIII con la intención de centralizar para unificar los reinos recién

\section{(이요 $\$$}


incorporados con la "nueva planta", en Nueva España no hubo ese problema, pues el virreinato se encontraba bajo las leyes de Castilla. Sin embargo, es en la segunda mitad del siglo cuando los reformistas borbones se dan cuenta de lo oportuno de estas modificaciones para recuperar el poder que habían perdido. Es decir, en España fue centralizar para unificar y en América fue reordenar para centralizar.

La Ordenanza de Intendentes fue la conclusión de los cambios que a lo largo de la primera mitad del siglo xviII se llevaron a cabo en España y de manera gradual en Nueva España. Esta Ordenanza es la organización y compilación de varias cédulas y reales órdenes expedida regularmente por la corona para desaparecer funciones y facultades e incluir nuevos oficiales que tendrían tareas más específicas.

La idea de crear líneas de autoridad y separar lo judicial de lo administrativo se hallaba presente cuando se intentaba reordenar la organización del Cabildo, pues se definían los ámbitos en los cuales tenía injerencia el Concejo y la manera en que podían disponer de sus fondos. Al disminuir facultades judiciales y fiscales se quedó con las administrativas, pero como un órgano de gobierno y administración de los intereses de los habitantes, donde la figura del virrey era muy importante.

El proyecto político-administrativo de los diputados en las Cortes de 1812 no se contraponía con el proyecto centralizador que la corona había llevado a cabo desde casi un siglo antes. En relación con el Ayuntamiento, este ya había sufrido importantes reformas que limitaban su poder de acción. Al no tomarse en cuenta las repercusiones que tuvo en la estructura y funciones del Cabildo novohispano la visita de José de Gálvez se da la impresión que los ayuntamientos creados luego de 1812 fueron un órgano completamente nuevo o por lo menos diferente a sus antecesores, con toda una carga política que les daba ser "la voz del pueblo" debido a que eran los encargados de realizar las elecciones dispuestas por la Constitución (Annino, 1992, pp. 121-158; Salinas, 2001). Sin embargo, esa era una de sus distintas funciones, ya que mientras adquirían esa tarea, muy importante desde luego, perdían discrecionalidad en otras ya que tuvo que supeditar sus acciones a nuevas instancias como el jefe político y la diputación provincial.

\section{(이)(1) $(2$}


Cuadro 2. Plan de comisiones del Ayuntamiento de la ciudad de México conforme al artículo 321 de la Constitución de 1812

Comisiones

1. La policía de salubridad y comodidad.

2. Auxiliar al alcalde en todo lo que pertenezca a la seguridad de las personas y bienes de los vecinos, $y$ a la conservación del orden público.

3. Administración de los propios y arbitrios, conforme a las leyes y reglamentos. Nombrar bajo su responsabilidad a un depositario.
Ramos

Integrantes
1. Juan Ignacio González Guerra

2. Ignacio Adalid

3. Juan de Antepara

4. Juan Vicente Gómez Pedrozo

5. Francisco Galicia

6. José Ma. Prieto de Bonilla

7. Conde la Presa de Xalpa

8. Marqués del Valleameno

9. Un síndico, por turno

1. Marqués del Valleameno

2. José Ma. Prieto de Bonilla

3. José Santos Vargas Machuca

4. Juan Orellana

5. Juan de Antepara incendios o cualquier otra cosa que exija su multiplicación.

Revisar las cuentas, expedir libramientos para los gastos ordinarios y extraordinarios de sus fondos. Controlar su distribución conforme al informe enviado a la comisión y los contratos realizados por la N. C.
1. Juan Ignacio González Guerra

2. Francisco Galicia

3. Conde de Valenciana

4. Rafael Márquez

\section{(이요 $\$$}


4. Hacer el repartimiento y recaudación de las contribuciones y remitirlas a la tesorería respectiva.

5. Cuidar de todas las escuelas de primeras letras, y de los demás establecimientos de educación que se paguen de los fondos del común.

6. Cuidar de los hospitales, hospicios, casas de expósitos y demás establecimientos de beneficencia bajo las reglas que se prescriben.

7. Cuidar de la construcción y reparación de caminos, calzadas, puentes y cárceles: de los montes y plantíos del común, y de todas las obras públicas de necesidad y ornato.

8. Formar las ordenanzas municipales del pueblo y presentarlas a las Cortes para su aprobación por medio de la Diputación Provincial, que las acompañara con su informe.
Lo que se indica

1. José Santos Vargas

2. Tomás Salgado

3. Antonio López Salazar

4. Ignacio Adalid

Lo que se indica

1. Tomás Salgado

2. Conde de la Valenciana
Lo que se indica

1. Antonio Salazar

2. Conde de la Presa de Xalpa

3. Juan Pérez Juárez

4. Francisco Villanueva
Acueductos

Ríos, calzadas y caminos

Puentes y obras públicas de utilidad y ornato.

Montes, plantíos del común.

Cárceles.

Lo que se indica
1. Juan de Orellana

2. Juan Vicente Gómez Pedrozo (encargado de acueductos, y de puentes y obras públicas)

3. José María Garay

4. José Santos Vargas Alcaldes ordinarios (2)

1. Tomás Salgado Los síndicos (2)

\section{(이요 $\circledast$}


9. Promover la agricultura, Lo que se indica

1. Rafael Márquez la industria y el comer-

2. Juan Orellana cio según la localidad

3. Juan Pérez Juárez y circunstancias de los

4. Francisco Manuel Sánpueblos, y cuanto les chez de Tagle sea útil y beneficioso.

Fuente: Plan de Comisiones de esta N. C. repartidas entre los individuos de su Ayuntamiento remitido a su excelencia y oficio de su aprobación, 4 fojas. Ayuntamiento. Comisiones. Vol. 406, exp. 10. 21 de abril de 1813. AHDF, México.

\section{LISTA DE REFERENCIAS}

Aguirre Anaya, C. (ed.) (2000). Los espacios públicos de la ciudad de México, siglos XVIII y XIX. México: Gobierno del Distrito Federal.

Annino, A. (septiembre-diciembre, 1992). Prácticas criollas y liberalismo en la crisis del espacio urbano colonial: el 29 de noviembre de 1812 en la ciudad de México. Secuencia. Revista de Historia y Ciencias Sociales [nueva época], 24, 121-158.

Bonnin, Ch.-J. (2003). Principios de administración pública. México: FCE.

Barrón Cruz, M. (2000). Modelos de la estructura administrativa del Ayuntamiento de la ciudad de México, del gobierno y del Departamento del Distrito Federal. En V. San Vicente (coord.), Archivo Histórico del Distrito Federal. Guía general. México: Gobierno del Distrito Federal.

Chust, M. (2007). La revolución municipal, 1810-1823. En J. Ortiz Escamilla y J. A. Serrano Ortega (eds.), Ayuntamientos y liberalismo gaditano en México. Zamora: El Colegio de Michoacán/Universidad Veracruzana.

Dávalos, M. (1997). Basura e ilustración; la limpieza de la ciudad de México a finales del siglo XVIII. México: INAH/DDF.

Domínguez Ortiz, A. (1990). Las claves del despotismo ilustrado, 1775-1789. España: Editorial Planeta.

Fernández Albaladejo, P. (1993). Monarquía, Cortes y cuestión constitucional en Castilla durante la edad moderna. En Fragmentos de monarquía. Trabajos de historia política. Madrid: Alianza Editorial.

Florescano, E. (1969). Precios del maíz y crisis agrícolas en México (1708-1810): ensayo sobre el movimiento de los precios y sus consecuencias económicas y sociales. México: Colmex.

\section{(이요 $\$$}


Fonseca F. y Urrutia, C. (1845). Historia general de Real Hacienda (vol. v). México: Vicente García Torres.

García García, C. (1996). La crisis de las Haciendas locales. De la reforma administrativa a la reforma fiscal (1743-1845). Valladolid: Junta de Castilla y León.

García-Baquero, G. (1993). Fortalecimiento de la centralización: la reforma de la administración. En A. Domínguez Ortiz (coord.), Historia de España. Barcelona: Editorial Planeta.

González Alonso, B. (1995). Las raíces ilustradas del ideario administrativo del moderantismo español. En De la Ilustración al liberalismo. Symposium en honor al profesor Paolo Grossi. Madrid: Centro de Estudios Constitucionales.

Guedea, V. (1992). En busca de un gobierno alterno: Los Guadalupes de México [Serie Historia Novohispana, 46]. México: IIH-UnAm.

Guerrero, O. (1994). Las raíces borbónicas del Estado mexicano. México: Coordinación de Humanidades-Dirección General de Publicaciones-unam.

Guillamón Martínez, J. (1980). Las reformas de la administración local durante el reinado de Carlos III. Un análisis de dos reformas administrativas de Carlos III. Madrid: Instituto de Estudios de Administración Local.

Hernández y Dávalos, J. E. (2006). Colección de documentos para la historia de la guerra de Independencia de México [facsímil, vol. iv]. V. Guedea y A. Ávila (dirs.). México: UNAM.

Hijano Pérez A. (julio- septiembre, 1996). Alcaldes constitucionales y jefes políticos: bases del régimen local en la primera etapa del constitucionalismo. Revista de Estudios Políticos (nueva época), 93, 259-271. Recuperado de http://www.cepc.gob.es/ publicaciones/revistas/revistaselectronicas?IDR=3\&IDN=250

Jáuregui, L. (1999). La Real Hacienda de Nueva España. Su administración en la época de los intendentes (1786-1821). México: Facultad de Economía-UnAM.

Mannori, L. y Sordi, B. (2004). Justicia y administración. En M. Fioravanti (ed.), El Estado moderno en Europa. Instituciones y derecho. Madrid: Editorial Trotta.

Merchan Fernández, A. C. (1988). Gobierno municipal y administración local en la España del antiguo régimen. Madrid: Editorial Tecnos.

Ohgaki Kodama, K. (1979). Ayuntamiento de la ciudad de México (1808-1821). La crisis política de 1808 y el camino constitucional. (Tesis de doctorado inédita). Colmex: México.

Pazos Pazos, M. L. (1999). El Ayuntamiento de la ciudad de México en el siglo xvir. Continuidad institucional y cambio social. Sevilla: Diputación de Sevilla.

Reinhard, W. (coord.) (1997). Las elites del poder y la construcción del Estado. México: FCE.

\section{()(1) $\$$}


Rodríguez O., J. E. (enero-abril, 2005). La naturaleza de la representación en Nueva España y México. Secuencia. Revista de Historia y Ciencias Sociales, 61, 7-32.

Rodríguez Kuri, A. (1994). Política e institucionalidad: El Ayuntamiento de México y la evolución del conflicto jurisdiccional, 1808-1850. En R. Hernández Franyutti (comp.), La ciudad de México en la primera mitad del siglo XIX (t. 2). México: Instituto Mora.

Salinas Sandoval, M. del C. (2001). Los municipios en la formación del Estado de México, 1824-1846. México: El Colegio Mexiquense.

Sánchez de Tagle, E. (2007). El privilegio, la ceremonia y la publicidad. Dilemas de los primeros regidores constitucionales de la ciudad de México. En B. Rojas (coord.), Cuerpo político y pluralidad de derechos. Los privilegios de las corporaciones novohispanas. México: CIDE/Instituto Mora.

Suárez Argüello, C. E. (2002). Informe del marqués de Sonora al virrey don Antonio Bucareli y Ursúa (estudio introductorio). México: ciesas/Porrúa.

Tanck de Estrada, D. (1999). Pueblos de indios y educación en el México colonial, 1750-1821. México: Colmex.

\section{OTRAS FUENTES}

AHDF Archivo Histórico del Distrito Federal, México.

AGN Archivo General de la Nación, México. 